\title{
E SE FREUD VISITASSE NOSSAS CRECHES: COMPASSOS E DESCOMPASSOS ENTRE CRIANÇAS E ADULTOS*
}

\author{
Cláudia Aparecida de Oliveira Leite, \\ do Espaço de Psicanálise Parlêtre, Divinópolis
}

\begin{abstract}
Resumo: Freud afirma que não precisaria ter escrito os Três ensaios sobre a teoria da sexualidade se os homens soubessem aprender através da observação direta das crianças. Para a Psicanálise, há um laço indissociável entre saber e subjetividade, pois a relação com o outro é fundamental para a construção de um saber. Consideramos que o encontro entre o adulto e a criança carrega em seu bojo a marca do descompasso de saber. Dessa maneira, destacamos, neste trabalho, que esse descompasso promove as vias do não saber, situando um movimento de aprender que se situa na experiência da criança e também na vivência do adulto.
\end{abstract}

Palavras-chave: Aprender. Psicanálise. Criança. Creche.

\section{I - APPREND'ER COM Freud}

A Psicanálise desde as primeiras elaborações de seu fundador, Sigmund Freud, destacou a importância das vivências infantis e a relevância das experiências da criança para a constituição do sujeito. Freud ([1905]1989, p. 126) afirma que não precisaria ter escrito os "Três ensaios sobre a teoria da sexualidade" se os homens soubessem aprender através da observação direta das crianças. Do legado deixado por ele, essa maneira peculiar de teorizar merece ser destacada, pois esse aprendizado fez-se presente ao longo de toda sua obra. Nós temos um exemplo disso em 1919, quando Freud, às voltas com a devastação deixada pela primeira grande guerra, pode formular sua reviravolta teórica, expressa no texto "Além do Princípio do Prazer" (1920), mediante a brincadeira de seu netinho. $O$ autor ([1920]1989, p. 25) diz:

\footnotetext{
* Artigo recebido em 5/1/2011 e aprovado em 7/8/2011.
} 
Sem querer incluir todo o campo abrangido por esses fenômenos, pude, através de uma oportunidade fortuita que se me apresentou, lançar certa luz sobre a primeira brincadeira efetuada por um menininho de ano e meio de idade e inventada por ele próprio. Foi mais do que uma simples observação passageira, porque vivi sob o mesmo teto que a criança e seus pais durante algumas semanas, e foi algum tempo antes que descobri o significado da enigmática atividade que ele constantemente repetia.

A brincadeira a que Freud se refere é o Fort-da. ${ }^{1}$ Freud observou que a criança lançava um carretel proferindo um expressivo "o-o-o-ó" (Fort = embora) e o puxava novamente saudando seu aparecimento alegremente, emitindo " $d a$ " (ali). Mediante a brincadeira do neto, Freud interpreta que se tratava de um jogo "relacionado à grande realização cultural da criança, a renúncia pulsional que efetuara ao deixar a mãe ir embora sem protestar" (FREUD ([1920]1989, p. 27). Esse elemento compõe a série argumentativa de Freud para rearticular os meandros da repetição, demarcando o "além do princípio do prazer"e propondo o dualismo pulsional configurado por pulsão de vida versus pulsão de morte.

Esses dois momentos da obra freudiana, em que a "observação" de crianças baliza a teorização do fundador da psicanálise, demarcam uma relação entre o posicionamento de Freud e a indicação que podemos reconhecer no verbo francês apprendre. A língua francesa reserva essa palavra, apprendre, para designar tanto o ato de ensinar quanto o ato de aprender. Essa constatação quebra um dualismo que muitas vezes é sustentado em nossa língua pela vigência de dois verbos que, conforme o sujeito que enuncia, demarca a escolha de um ato em detrimento do outro.

Buscamos, neste trabalho, discutir sobre o modo como apprendr'emos ${ }^{2}$ hoje no compromisso educativo e relacional que estabelecemos com a criança. Mantemos para isso, a posição freudiana que demarcou em sua teoria a pertinência de aprender através das crianças. Se Freud visitasse nossas creches, o que aprenderia? Será que não estamos por demais preocupados em ensinar as crianças, deixando escapar a potência do aprender embutido em todo ato de ensinar? Situamos tais perguntas delineando a perspectiva da psicanálise que considera a dimensão subjetiva impressa no ato de aprender.

\section{II - COMPASSOS E DESCOMPASSOS: A CONSTITUIÇÃO DO SUJEITO}

Ao articular o saber pela via da subjetividade, a teoria psicanalítica privilegia o laço relacional, pois considera que os movimentos singulares que constituem o sujeito estão intimamente enlaçados ao semelhante. Tal operação é fundamental porque o bebê humano nasce estruturalmente 
desamparado, tendo, portanto, necessidade vital de um outro que dispense cuidados para que ele sobreviva e que dispense palavras para que ele se aproprie do seu corpo e do seu nome. Em outras palavras, para que o sujeito se constitua é preciso que já haja um lugar para ele delineado na ordem simbólica, no discurso daqueles que se dedicarão a apostar em seu advento. Nesse aspecto, encontramos a assertiva de Lacan ([1957]1998, p. 498) que demarca que "também o sujeito, se pode parecer servo da linguagem, o é ainda mais de um discurso em cujo movimento universal seu lugar já está inscrito em seu nascimento, nem que seja sob a forma de seu nome próprio". Sobre o nome próprio, destacamos a potência da nomeação que incide radicalmente na constituição subjetiva, pois o nome próprio promove a passagem da carne (organismo) ao corpo. $\mathrm{O}$ ato de nomear, realizado por um Outro que antecede o sujeito, no mesmo movimento em que traz ao humano significação, sentido e corpo próprio, também incide como um traço, esvaziado de sentido. ${ }^{3} \mathrm{O}$ nome próprio, exatamente por ser tomado nessa dupla dimensão - na função significante e na função objetal - articula a dimensão do corpo. Por esse aspecto, um dos meios de escuta significativos nas instituições educacionais é dar lugar ao nome próprio da criança, já que este aponta correntemente para a problemática da filiação e da sexuação.

A antecipação fundamental da criança no discurso do adulto delineia, portanto, um lugar e imprime marcas que serão apropriadas por ela. Dessa tessitura, para ter acesso ao próprio desejo, o sujeito primeiramente viverá sua alienação no desejo do Outro e, conforme os desdobramentos de sua vivência, demarcará sua separação desse desejo. Assim, os movimentos lógicos que implicam a constituição subjetiva, e que entram em jogo na atribuição de um lugar à criança no discurso familiar, estão intimamente ligados aos personagens que atuam em seu entorno.

Essa implicação relacional que funda o humano foi demarcada por Freud desde 1895, em seu "Projeto para uma psicologia científica". Nele, Freud ([1895]1950, p. 383) argumenta:

Suponhamos que o objeto que compõe a percepção se pareça com o sujeito - um outro ser humano. Nesse caso, o interesse teórico [que lhe é dedicado] também se explica pelo fato de que um objeto semelhante foi, ao mesmo tempo, o primeiro objeto hostil, além de sua única força auxiliar. Por esse motivo, é em relação a seus semelhantes que o ser humano aprende a conhecer. (Grifos nossos)

Para Freud, é nesse encontro com o semelhante que o humano aprende a conhecer (reconhecer). Essas palavras não devem ser negligenciadas. Entre o adulto e a criança há um encontro do aprender; encontro descompassado que carrega em seu bojo as vias do desejo e do saber. 


\section{III - DeSEJO E SABER}

Vorcaro (2008, p. 2) afirma que "afinal, enquanto o infans e o adulto estão ambos imersos no campo simbólico onde as estruturas discursiva e significante operam, esta imersão não é a mesma". Em concordância com a autora, podemos considerar que estruturalmente a posição da criança e a posição do adulto não podem ser coincidentes.

Entretanto, esse descompasso na imersão simbólica não pode ser tomado como um meio de silenciamento da criança, visto que, pautados nas considerações psicanalíticas, podemos entender o saber estabelecido na construção da cadeia significante, na operação da fala. Portanto, a psicanálise reserva ao saber um furo. Lacan, ao configurar os quatro discursos, destaca que o saber, $\mathrm{S}_{2}$ ocupa o lugar da verdade no discurso analítico. Essa posição gera incômodo, pois em posição de verdade, o saber não pode ser completamente dito. Sempre fica um resto insabido, um furo que permite manter o movimento da cadeia. Tal descompasso, que promove em seu avesso as vias do não saber, estabelece um laço entre saber e desejo.

Podemos constatar que a criança interroga continuamente o saber do adulto, delineando, nessa interrogação, os furos desse saber. Dessa maneira, permitir contar com esse furo na prática educativa é abrir as portas para causar o desejo na criança e, com esse desejo, destacar a dimensão de saber que lhe é própria. Talvez seja nesse sentido que podemos destacar a seguinte contribuição de Lajonquière (2002, p. 137):

Como vemos, a introdução da "criança" no real de uma história em curso não faz mais do que instaurar uma tensão no campo do discurso entre o lado de lá - o do infans - e este outro de cá - o do adulto. Onde ambos não são pontos de uma linha genético-evolutiva rumo a uma razão mais ou menos iluminada, mas posições no discurso com relação ao desejo. Para que semelhante giro de posição aconteça é necessário que o adulto tome como metáfora o desencontro no real com esse pequeno ser no mundo. Educar é isso; é transmitir marcas simbólicas - inventar metáforas - que possibilitem ao pequeno sujeito usufruir de um lugar a partir do qual possa se lançar às empresas impossíveis do desejo. Esse giro de posição no campo da palavra e da linguagem é a própria condição de possibilidade de que venha a ex/ istir um tempo de infância.

Educar está intimamente ligado às empresas do impossível: ao desejo do sujeito e ao saber enquanto furo. É nesse sentido, que o estabelecimento da posição de apprendre pode permitir um modo diferenciado de relação educacional. 


\section{IV - PSICANÁLISE E EDUCAÇÃO: CONSIDERAÇõES}

Os apontamentos presentes neste trabalho nasceram da experiência de supervisão em estágio de Psicologia em creches. O estágio traz sempre uma experiência interessante, pois o estudante de Psicologia se encontra em posição de aprender, ainda que ele reúna uma quantidade considerável de conhecimento sobre determinado tema que lhe permite ensiná-lo. Ao mesmo tempo, ele se inclina sobre as crianças, professores, instituição e sobre o próprio aprender. A posição do estagiário pode ser delineada como a posição de apprendre (ensinar/aprender) por excelência. Posição, ao nosso ver, indicada por Freud.

Propomos esse ponto de encontro entre psicanálise e educação; ponto em que os agentes do processo partilham singularmente da posição de apprendre. Obviamente, do lugar de adulto, a relação com o conhecimento e saber já permite transmissão. $O$ adulto sabe. Sabe inclusive que não sabe. Essa é uma proposta desse trabalho, destacar o aprender que se situa do lado do adulto, daquele que propõe um encontro educativo com essa criança.

O impossível da tarefa educativa se estabelece no justo domínio da subjetividade e do desejo. Se por um lado, pelo compasso da linguagem estabelecemos laços sociais, por outro lado, o desejo formula um descompasso, pois relança continuamente a falta. A tarefa educativa inclui essa pulsação, esse abre-fecha entre a constituição de um sujeito, ou seja, a constituição de um desejante e a tarefa de confrontá-lo com o outro, com a cultura, com o limite do gozo. De algum modo, isso se dá dos dois lados: do lado da criança e do lado do adulto.

\section{IF FREUD WERE TO VISIT OUR NURSERY SCHOOLS: MATCHES AND MISMATCHES BETWEEN CHILDREN AND ADULTS}

ABSTRACT: Freud says that he would not need to have written the Three Essays on the Theory of Sexuality if people knew how to learn from the direct observation of children. For Psychoanalysis, there is an indissoluble link between knowledge and subjectivity, since the relationship with the other is fundamental for building knowledge. We believe that the meeting between adult and child carries within it the signs of a mismatch in knowledge. By sharing this point of view, we emphasize in this study that such a mismatch in knowledge promotes ways of not-knowing, leading to a movement of learning located in both the child's experience and in that of the adult.

KEYwords: Learning. Psychoanalysis. Child. Nursery schools. 


\section{NOTAS}

1. Fort é um advérbio alemão empregado na expressão 'ir embora', enquanto da significa "ali, lá". Essa brincadeira é frequentemente encontrada entre crianças, e em nossa língua se estabelece pela dupla "escondeu-achou".

2. Escolhemos criar um neologismo considerando o verbo francês apprendre como forma de não separar a relação ensinar-aprender.

3. Sobre esse tema, ver Leite (2008).

\section{REFERÊNCIAS}

FREUD, Sigmund. Três ensaios sobre a teoria da sexualidade. Edição Standard Brasileira das obras completas de Sigmund Freud. Tradução de J. Salomão. Rio de Janeiro: Imago, 1989. v. VII.

FREUD, Sigmund. Além do princípio do prazer. Edição Standard Brasileira das obras completas de Sigmund Freud. Tradução de J. Salomão. Rio de Janeiro: Imago, 1989. v. XVIII.

FREUD, Sigmund. Projeto para uma psicologia científica. Edição Standard Brasileira das obras completas de Sigmund Freud. Tradução de J. Salomão. Rio de Janeiro: Imago, 1988. v. I.

LACAN, Jacques. A instância da letra no inconsciente. Escritos. Rio de Janeiro: Jorge Zahar, 1998.

LAJONQUIÈRE, Leandro. A psicanálise, a educação e o esgotamento da infância. Anais do III Colóquio do LEPSI. In: KUPFER, M. C.; LAJONQUIÈRE, L. (Orgs.). São Paulo: Ed. da USP, 2002.

LEITE, C. A. O. Quando o corpo pede um nome: a título provisório. Tese (Doutorado) Universidade de Campinas, Campinas-SP, 2008.

VORCARO, Ângela. Desastre e acontecimento na estrutura. Belo Horizonte, 2008. (Inédito).

Cláudia Aparecida de Oliveira leite possui graduação em Psicologia pela Universidade Federal de Minas Gerais, mestrado em Linguística e doutorado em Linguística pela Universidade Estadual de Campinas. É pesquisadora do Projeto SEMA $\$ 0 M a$ (Unicamp) e membro fundadora do Parlêtre: Psicanálise, Pesquisa e Transmissão. Tem experiência na área de Psicologia e Psicanálise, atuando principalmente nos seguintes temas: psicanálise, nome próprio, clínica psicanalítica, linguagem, escrita, sujeito.

E-mail: caoleite@yahoo.com.br 